\title{
Implementasi Metode Electre Dalam Menentukan Klasifikasi Hotel
}

\author{
Billy Eden William Asrul, Sitti Zuhriyah ${ }^{2}$ \\ ${ }^{1}$ Teknik Informatika, STMIK Handayani, ${ }^{2}$ Sistem Komputer, STMIK Handayani \\ billy@handayani.ac.id,zuhriyah@handayani.ac.id, \\ Coprespondent Author :bewagabriel.bg@gmail.com
}

\begin{abstract}
Business certification institutes as the authority to determine the classification of hotels based on hotel class, synergize with the tourism department, hotel and restaurant assemblies in the process of audit, construction and supervision. The implementation of tourism business certification in the city of Makassar still needs to be improved in effectiveness and efficiency, cheap, easy and fast. to solve the problem created a system to support hotel classification decisions, this system implements Electre methods in processing data so as to speed up the process of classifying hotel status, facilitate auditors in conducting audit processes, assist in the implementation of periodic inspections. The ELECTRE method provides multicriteria results with the concept of outranking comparisons of pairs of alternatives based on appropriate criteria. The accuracy test result of the system is $85.71 \%$ with 15 test data.
\end{abstract}

Keyword - Hotel Classification, ELECTRE, Hotel Certification.

Abstrak - Lembaga sertifikasi usaha sebagai badan yang berwenang menentukan klasifikasi hotel berdasarkan kelas hotel, bersinergi dengan dinas pariwisata, perhimpunan hotel dan restoran dalam proses audit, pembinaan dan pengawasan. pelaksanaan sertifikasi usaha pariwisata di kota makassar masih perlu ditingkatkan secara efektivitas dan efisiensi, murah, mudah dan cepat. untuk mengatasi masalah tersebut dibuat sebuah sistem pendukung keputusan klasifikasi hotel, sistem ini mengimplementasikan metode Electre dalam mengolah data sehingga mempercepat proses klasifikasi status hotel, memudahkan auditor dalam melakukan proses audit, membantu pelaksanaan pengawasan secara periodik. Metode ELECTRE memberikan keputusan multikriteria dengan konsep outranking perbandingan berpasangan dari alternatif-alternatif berdasarkan kriteria yang sesuai. Hasil uji akurasi dari sistem sebesar $85,71 \%$ dengan data uji sebanyak 15 data.

Kata kunci - Klasifikasi Hotel, ELECTRE, Sertifikasi Hotel.

\section{PENDAHULUAN}

Pariwisata seringkali dipersepsikan sebagai mesin ekonomi penghasil devisa, namun demikian pada prinsipnya pariwisata memiliki spectrum fundamental pembangunan yang lebih luas dan pada dasarnya ditujukan untuk meningkatkan persatuan dan kesatuan, penghapusan kemiskinan (poverty alleviation); pembangunan berkesinambungan (sustainable development), pemenuhan kebutuhan hidup dan hak azasi manusia, peningkatan ekonomi dan industri kreatif; dan pengembangan teknologi.

Pengembangan kepariwisataan bergantung pada keunggulan daya tarik wisata, kualitas sarana dan prasarana di destinasi wisata, dan keberadaan industri pariwisata sebagaimana termaktub dalam Undang-Undang Nomor 10 Tahun 2009 tentang Kepariwisataan yang menyebutkan bahwa produk, pelayanan dan pengelolaan usaha pariwisata memiliki standar usaha. Sertifikasi Usaha Pariwisata sangat diperlukan dan dibutuhkan untuk mendukung pengembangan kegiatan kepariwisataan nasional dalam menghadapi persaingan globalisasi dan liberalisasi sektor jasa baik di tingkat regional dan internasional [1].

Jumlah penduduk Kota Makassar yang mencapai 1,4 juta jiwa dengan luas 175,79 km2 menjadikan Makassar sebagai gerbang di Kawasan Timur Indonesia (KTI) dimana Makassar terletak dititik nol Indonesia. Kota Makassar yang terposisi sebagai ibu kota propinsi Sulawesi Selatan sekaligus merupakan Living Room Kawasan Timur Indonesia memiliki usaha pariwisata yang potensial untuk dapat dikembangkan sebagai industry pariwisata berkelas dunia dengan produk, pelayanan dan pengelolaan yang terstandar. Industry seperti hotel dan penginapan, restoran dan rumah makan merupakan beberapa jenis usaha yang berkembang pesat di Kota Makassar yang dapat kita jumpai di setiap sudut kota.

Usaha industry pariwisata khususnya hotel yang setiap tahun meningkat harus didukung dengan peningkatan kualitas pelayanan pariwisata bagi para wisatawan yang sesuai dengan standar usaha pariwisata yang berdasarkan pada Peraturan Pemerintah Nomor 52 tahun 2012 tentang Sertifikasi Kompetensi dan Sertifikasi Usaha di Bidang Pariwisata yang kemudian ditindaklanjuti dengan Peraturan Menteri Pariwisata dan Ekonomi Kreatif Nomor PM.53/HM.001/MPEK/2013 tentang Standar Usaha Hotel yang mengatur tentang standard dan klasifikasi hotel, mengatur tentang penentuan dan kelayakan sebuah hotel mulai dari bintang I, II, III, IV dan V [2].

Melalui tahapan sertifikasi usaha meliputi Permohonan sertifikasi, Penawaran biaya, Perjanjian Kerjasama [3], Program Audit, Pelaksanaan Audit, Penerbitan Sertifikat Penilaian hotel bintang kemudian diaudit oleh Lembaga Sertifikasi Usaha Pariwisata dilaksanakan secara manual dengan mengaudit kesesuaian antara standard dan kondisi real pada ketiga aspek (produk, pengelolaan dan pelayanan). Proses audit ini biasanya membutuhkan waktu yang agak lama dengan adanya banyak variable yang menjadi acuan penelitian. Berdasarkan hal tersebut maka peneliti membuat suatu sistem pendukung keputusan yang dapat membantu tim audit dalam melakukan penilaian klasifikasi hotel. 
Sistem yang dibuat mengimplementasikan metode ELECTRE dalam mengolah variabel-variabel penelitian. Peneliti memilih metode ELECTRE karena metode ELECTRE dapat memberikan keputusan multikriteria dengan konsep outranking perbandingan berpasangan dari alternatif-alternatif berdasarkan kriteria yang sesuai [4]. Penggunaan metode ELECTRE sangat sesuai digunakan untuk kasus yang melibatkan banyak alternatif namun kriteria yang sedikit [5].

Pada penelitian sebelumnya metode ELECTRE digunakan untuk pemilihan usaha kecil home industry yang tepat bagi mahasiswa [6]. Selain itu, metode ELECTRE juga telah diaplikasikan pada sistem untuk memilih mahasiswa yang tepat sebagai penerima beasiswa [7]. Pada penelitian lainnya, metode ELECTRE digunakan untuk memberikan rekomendasi pemilihan Sekolah Menengah Atas dan sederajat yang ada di Kota Malang, hasil uji akurasi dari ketepatan pemilihan SMA sebesar 82,98\% [8].

\section{TINJAUAN PUSTAKA}

\section{A. Metode ELECTRE}

Metode Electre merupakan salah satu metode pengambilan keputusan berdasarkan outranking dengan membandingkan setiap alternatif dari semua kriteria secara terpisah. Selain itu, ELECTRE dapat digunakan untuk pengambilan keputusan yang bersifat multikriteria dengan menghilangkan alternatif yang kurang sesuai dengan kriteria [9].

Langkah-langkah dari metode ELECTRE adalah sebagai berikut [10] [11]:

a. Normalisasi matriks keputusan

Dalam proses normalisasi matrik setiap atribut akan diubah menjadi nilai yang comparatable.

b. Pembobotan Matriks

Tahap selanjutnya adalah pemberian bobot pada matriks yang dinormalisasi, dengan mengalikan setiap elemen-elemen pada matriks dengan bobotbobot yang telah ditentukan. Formula yang digunakan dalam pembotoan matriks yaitu:

$$
\mathrm{V}=\mathrm{R} \times \mathrm{W}
$$

c. Himpunan Concordance dan Discordance

Setiap pasang alternatif $\mathrm{k}$ dan $1(\mathrm{k}, 1=1,2,3, \ldots \mathrm{m}$ dan $\mathrm{k}, \mathrm{l}$ ), untuk nilai $\mathrm{j}$ merupakan nilai dari concordance dan discordance. Formula untuk menghitung Concordance dan Discordance. Berikut formula untuk menetukan Concordance dan Discordance.

Concordance:
$C_{k \mathbb{N}}=\left\{\hat{j}_{i} \cdot y_{k j} \geq y_{i j}\right\}$
Disconcordance:

$$
\left.D_{k l}=j_{i} y_{k j}<y_{i j}\right\}
$$

d. Matriks Concordance dan Disconcordance

Setelah menentukan himpunan dari Concordance dan Disconcordance, maka langkah selanjutnya adalah menentukan elemen-elemen matriks concordance dan disconcordance. Berikut rumus untuk menentukan matriks Concordance dan Discordance:

\section{Concordance}

$c_{\mathrm{kl}}=\Sigma_{j C_{\mathrm{kl}}} w_{j}$

Matriks Concordance:

$$
C=\left[\begin{array}{ccccc}
- & c_{12} & c_{13} & \cdots & c_{1 n} \\
c_{21} & - & c_{23} & \cdots & c_{2 n} \\
\cdots & & & & \\
c_{m 1} & c_{m 2} & c_{m 3} & \cdots & -
\end{array}\right]
$$

Discordance:

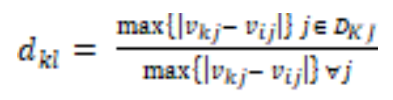

Matriks Discordance:

$$
D=\left[\begin{array}{ccccc}
- & d_{12} & d_{13} & \ldots & d_{1 m} \\
d_{21} & - & d_{23} & \ldots & d_{2 m} \\
\cdots & & & & \\
d_{m 1} & d_{m 2} & d_{m 3} & \cdots & -
\end{array}\right]
$$

e. Menentukan Matriks dominan concordance dan disconcordance

1. Matriks dominan concordance

Nilai matriks dominan concordance dihitung dengan bantuan nilai threshold, yaitu dengan membandingkan antara nilai threshold dengan nilai elemen matriks concordance. Rumus yang digunakan adalah,

$$
C_{\text {kil }} \geq c
$$

Dengan nilai threshold ( c ) adalah

$$
C=\frac{\sum_{k=1}^{m} \sum_{l=1}^{m} c_{k l}}{m(m-1)}
$$

Dengan demikian elemen matriks F adalah: 


$$
f_{k l}=\left\{\begin{array}{l}
1, j i k a c_{k l} \geq c \\
0, j i k a c_{k l}<c
\end{array}\right\}
$$

2. Matriks dominan disconcordance

Matriks dominan disconcordance ditentukan dengan menggunakan bantuan nilai threshold,

$$
D=\frac{\sum_{k=1}^{m} \sum_{l=1}^{m} d_{k l}}{m(m-1)}
$$

Dengan demikian elemen matriks $\mathrm{G}$ adalah:

$$
G_{k l}=\left\{\begin{array}{l}
1, \text { jika } d_{k l} \geq d \\
0, j i k a d_{k l}<d
\end{array}\right\}
$$

f. Menentukan agregat dominance matriks

Elemen matriks agregat dominance diperoleh dari hasil perkalian antara elemen matriks $\mathrm{F}$ dan Elemen matriks $\mathrm{G}$, dengan rumus sebagai berikut:

$$
e_{k l}=f_{k l} \times g_{k l}
$$

g. Menentukan Less Favourable

Dari matriks agregat dominance dapat dilihat urutan nilai setiap alternatif. Jika $\theta_{k l}=1$ maka alternatif $A_{k}$ merupakan pilihan terbaik daripada $A_{1}$, dengan terdapat $e_{k l}=1$ yang dapat dieliminasi dari matrikd agregat $\mathrm{E}$.

\section{B. Sertifikasi Hotel}

Sertifikasi Usaha Pariwisata untuk hotel adalah memberikan pengakuan independen bahwa sistem manajemen dari suatu usaha pariwisata tersebut telah. sesuai dengan standar yang ditentukan, mampu mencapai kebijakan dan sasaran yang ditetapkan secara konsisten; dan, diimplementasikan secara efektif dan efisien. Oleh karena itu, sertifikasi usaha pariwisata untuk hotel memberikan kepastian kepada usaha pariwisata itu sendiri dan pelanggan, serta pihak-pihak yang berkepentingan. Kegiatan sertifikasi mencakup audit terhadap 3 (tiga) aspek standar usaha pariwisata yang meliputi aspek produk, pelayanan dan pengelolaan. Bentuk pengesahan kesesuaian terhadap standar usaha pariwisata adalah Sertifikat Usaha Pariwisata. Sertifikasi usaha untuk hotel ini juga menjadi dasar penetapan klasifikasi bintang suatu hotel.

\section{METODE PENELITIAN}

Tahapan penelitian ini terdiri dari 5 tahap. Tahapan penelitian tersebut dijelaskan sebagai berikut:

a. Identifikasi masalah

Langkah pertama yang dilakukan oleh peneliti melakukan survey ke lokasi penelitian, terkait masalah yang dihadapi. Hal ini sangat penting sebagai landasan awal melakukan penelitian.

\section{b. Studi literatur}

Setelah mengidentifikasi masalah yang dihadapi mitra penelitian maka selanjutnya adalah melakukan kajian literatur yang berkaitan dengan penelitian yang akan dilakukan.

\section{c. Pengumpulan data}

Data yang dikumpulkan terdiri dari data primer dan data sekunder. Data primer didapat dari hasil wawancara langsung dari narasumber di lokasi penelitian, dalam hal ini Dinas Pariwisata kota Makassar dan LSUP kota Makassar, sedangkan data sekunder diperoleh dari data yang telah ada sebelumnya. Data yang dimaksud di sini adalah data-data hotel yang ada di kota Makassar.

d. Perancangan sistem'

Dari proses identifikasi masalah dan pengumpulan data, maka peneliti melakukan perancangan sistem yang dapat menyelesaikan permasalahan yang dihadapi oleh mitra, dalam hal ini Dinas Pariwisata kota Makassar. Sistem yang akan dibuat merupakan sistem pendukung keputusan berbasis website.

e. Implementasi algoritma

Pada tahap ini data yang sudah diolah akan dianalisis dengan menggunakan metode ELECTRE, untuk menentukan klasifikasi hotel.

\section{f. Pengujian sistem}

Langkah akhir dari penelitian ini adalah dilakukan pengujian sistem. Pengujian dilakukan dua tahap yaitu pengujian sistem yang dilakukan oleh user dalam hal ini pihak Dinas Pariwisata kota Makassar dan LSUP Kota Makassar. Tahapan pengujian selanjutnya adalah pengujian sistem yang dilakukan oleh pembuat sistem.

\section{HASIL DAN PEMBAHASAN}

Data yang digunakan dalam penelitian diperoleh dari dua sumber yang berbeda yaitu, dari Dinas Pariwisata kota Makassar selaku instansi yang melakukan pengawasan dan data dari LSUP sebagai lembaga yang melakukan audit.

Data yang diperoleh dari Dinas Pariwisata Kota Makassar sebagai berikut:

1. Data hotel yang berdasarkan self assessment yang diklasifikasikan berdasarkan jumlah kamar dan tempat tidur, serta fasilitas yang ditawarkan.

2. Data hotel yang telah mendapatkan sertifikat dari LSUP.

Data yang diperoleh dari LSUP sebagai lembaga adalah:

1. Informasi mengenai dasar penilaian audit meliputi Persyaratan fisik (berupa lokasi hotel dan kondisi bangunan), Jumlah kamar yang tersedia, Bentuk pelayanan yang diberikan, Kualifikasi tenaga kerja (berupa pendidikan dan kesejahteraan karyawan), 
Fasilitas olahraga dan rekreasi lainnya yang tersedia seperti kolam renang lapangan tenis dan diskotik.

2. Informasi mengenai syarat penilaian hotel yang dilakukan oleh tim audit, rentang nilai yang digunakan dalam penilaian hotel berbintang sebagai berikut:

a. $\geq 936$ untuk kelas hotel bintang lima;

b. 728 - 916 untuk kelas hotel bintang empat;

c. 520 - 708 untuk kelas hotel bintang tiga;

d. $312-500$ untuk kelas hotel bintang dua; dan

e. $208-292$ untuk kelas hotel bintang satu.

\section{A. Implementasi Algoritma}

Algoritma yang digunakan dalam penelitian ini adalah metode ELECTRE, pemilihan metode ELECTRE karena mampu memberikan hasil yang optimal yang melibatkan banyak alternatif. Berikut dijabarkan kriteria-kriteria yang digunakan dalam penelitian:

Tabel. 1 Kriteria-kriteria Penilaian klasifikasi Hotel

\begin{tabular}{|c|c|c|c|}
\hline No & Kriteria & Fasilitas & Nilai \\
\hline 1 & kamar & $\begin{array}{l}10-49 \\
50-99 \\
>100\end{array}$ & $\begin{array}{l}1 \\
1 \\
1\end{array}$ \\
\hline 2 & kolam renang & $\begin{array}{l}\text { Ada } \\
\text { Tidak ada }\end{array}$ & $\begin{array}{c}20 \\
0\end{array}$ \\
\hline 3 & Ruang Meeting & $\begin{array}{l}\text { Ada } \\
\text { Tidak ada }\end{array}$ & $\begin{array}{c}20 \\
0\end{array}$ \\
\hline 4 & Ball room & $\begin{array}{l}\text { Ada } \\
\text { Tidak ada }\end{array}$ & $\begin{array}{c}20 \\
0\end{array}$ \\
\hline 5 & Restauran & $\begin{array}{l}\text { Ada } \\
\text { Tidak ada }\end{array}$ & $\begin{array}{c}20 \\
0\end{array}$ \\
\hline 6 & Area Parkir & $\begin{array}{l}\text { Luas } \\
\text { Sempit } \\
\text { Tidak ada }\end{array}$ & $\begin{array}{c}90 \\
45 \\
0 \\
\end{array}$ \\
\hline 7 & Fitnes Room & $\begin{array}{l}\text { Ada } \\
\text { Tidak ada }\end{array}$ & $\begin{array}{c}20 \\
0 \\
\end{array}$ \\
\hline 8 & Mall & $\begin{array}{l}\text { Ada } \\
\text { Tidak ada }\end{array}$ & $\begin{array}{c}100 \\
0\end{array}$ \\
\hline 9 & Wifi & $\begin{array}{l}\text { Ada } \\
\text { Tidak ada }\end{array}$ & $\begin{array}{c}20 \\
0\end{array}$ \\
\hline 10 & Roomserv & $\begin{array}{l}\text { Ada } \\
\text { Tidak ada }\end{array}$ & $\begin{array}{c}20 \\
0\end{array}$ \\
\hline 11 & Bus & $\begin{array}{l}\text { Ada } \\
\text { Tidak ada }\end{array}$ & $\begin{array}{c}20 \\
0\end{array}$ \\
\hline 12 & Laundry & $\begin{array}{l}\text { Ada } \\
\text { Tidak ada }\end{array}$ & $\begin{array}{c}20 \\
0 \\
\end{array}$ \\
\hline 13 & Drugst & $\begin{array}{l}\text { Ada } \\
\text { Tidak ada }\end{array}$ & $\begin{array}{c}20 \\
0\end{array}$ \\
\hline 14 & Salon & $\begin{array}{l}\text { Ada } \\
\text { Tidak ada }\end{array}$ & $\begin{array}{c}20 \\
0\end{array}$ \\
\hline 15 & Karyawan & $\begin{array}{l}\text { Ada } \\
\text { Tidak ada }\end{array}$ & $\begin{array}{l}1 \\
0\end{array}$ \\
\hline 16 & Pelayanan & $\begin{array}{l}\text { Height } \\
\text { Medium } \\
\text { Low }\end{array}$ & $\begin{array}{c}100 \\
50 \\
25\end{array}$ \\
\hline
\end{tabular}

Bobot untuk setiap kriteria adalah sebagai berikut:

Tabel 2. Bobot setiap kriteria

\begin{tabular}{|c|l|c|}
\hline $\begin{array}{c}\text { Id } \\
\text { Kriteria }\end{array}$ & \multicolumn{1}{|c|}{ Kriteria } & Weight \\
\hline 1 & Kamar & 15 \\
\hline 2 & Kolam Renang & 5 \\
\hline 3 & Ruang Meeting & 10 \\
\hline 4 & Ball Room & 10 \\
\hline 5 & Restauran & 10 \\
\hline 6 & Area Parkir & 5 \\
\hline 7 & Fitness Room & 5 \\
\hline 8 & Mall & 10 \\
\hline 9 & wifi & 5 \\
\hline 10 & roomserv & 5 \\
\hline 11 & bus & 5 \\
\hline 12 & Loudry & 5 \\
\hline 13 & Drugst & 5 \\
\hline 14 & Salon & 5 \\
\hline 15 & Karyawan & 25 \\
\hline 16 & Pelayanan & \\
\hline
\end{tabular}

Setelah ditentukan bobot untuk kriteria maka dilakukan penginputan nilai kriteria untuk setiap hotel. Pada tabel 3, diberikan contoh penginputan nilai kriteria setiap hotel.

Tabel.3. contoh penginputan nilai kriteria setiap hotel

\begin{tabular}{|c|l|c|c|c|c|c|}
\hline No & kriteria & $\begin{array}{c}\text { anging } \\
\text { mammiri }\end{array}$ & Alden & $\begin{array}{c}\text { Arya } \\
\text { Duta }\end{array}$ & $\begin{array}{c}\text { Sahid } \\
\text { Jaya }\end{array}$ & ramedo \\
\hline 1 & kamar & 26 & 50 & 224 & 220 & 83 \\
\hline 2 & $\begin{array}{l}\text { kolam } \\
\text { renang }\end{array}$ & 0 & 0 & 20 & 20 & 0 \\
\hline 3 & $\begin{array}{l}\text { ruang } \\
\text { meeting }\end{array}$ & 20 & 60 & 120 & 120 & 120 \\
\hline 4 & ballroom & 0 & 0 & 80 & 120 & 40 \\
\hline 5 & restauran & 20 & 0 & 20 & 20 & 20 \\
\hline & $\begin{array}{l}\text { area } \\
\text { parkir }\end{array}$ & 0 & 45 & 180 & 180 & 90 \\
\hline 7 & $\begin{array}{l}\text { fitnes } \\
\text { room }\end{array}$ & 0 & 0 & 20 & 0 & 0 \\
\hline 8 & mall & 0 & 0 & 0 & 0 & 0 \\
\hline 9 & wifi & 20 & 20 & 40 & 40 & 400 \\
\hline 10 & roomserv & 20 & 20 & 20 & 20 & 0 \\
\hline 11 & bus & 0 & 0 & 40 & 40 & 0 \\
\hline 12 & laundry & 20 & 0 & 20 & 0 & 20 \\
\hline 13 & drugst & 20 & 0 & 20 & 20 & 0 \\
\hline 14 & salon & 0 & 0 & 20 & 20 & 0 \\
\hline 15 & karyawan & 21 & 24 & 205 & 111 & 37 \\
\hline 16 & pelayan & 100 & 50 & 100 & 100 & 50 \\
\hline & & & & & \\
\hline
\end{tabular}


Setelah dilakukan penginputan nilai kriteria setiap hotel, maka dilakukan analisis nilai kriteria dengan menggunakan metode ELECTRE, dengan langkah-langkah algoritma seperti yang dijabarkan pada tinjauan pustaka.

Nilai-nilai kriteria yang diinput dianalisis secara matematis sesuai dengan langkah-langkah metode ELECTRE. Hasil analisis dari tahap awal sampai akhir diberikan pada tabel berikut:

Tabel 4. Hasil Prediksi klasifikasiMenggunakan Metode ELECTRE

\begin{tabular}{|c|l|c|}
\hline No & \multicolumn{1}{|c|}{ Hotel } & Data Prediksi \\
\hline 1 & Anging Mammiri & Bintang 1 \\
\hline 2 & Alden & Bintang 2 \\
\hline 3 & Arya Duta & Bintang 5 \\
\hline 4 & Sahid Jaya Hotel & Bintang 5 \\
\hline 5 & Ramedo & Bintang 4 \\
\hline
\end{tabular}

Tabel 5. Data Klasifikasi Bintang Hotel dari Dinas Pariwisata

\begin{tabular}{|c|l|c|}
\hline No & \multicolumn{1}{|c|}{ Hotel } & Data Aktual \\
\hline 1 & Anging Mammiri & Bintang 1 \\
\hline 2 & Alden & Bintang 2 \\
\hline 3 & Arya Duta & Bintang 5 \\
\hline 4 & Sahid Jaya Hotel & Bintang 5 \\
\hline 5 & Ramedo & Bintang 3 \\
\hline
\end{tabular}

Dari data yang ditampilkan pada tabel 4 dan tabel 5, akan dihitung uji akurasi dari penerapan Metode ELECTRE. Pengujian akurasi menggunakan Confusion Matrix. Rumus confusion matrix sebagai berikut:

$$
\text { Akurasi }=\frac{T P+T N}{T P+T N+F P+F N} \times 100 \%
$$

Ket:

a. TP $($ True Positive $)=$ Jumlah prediksi yang benar dari data yang relevan.

b. FP (False Positive) = Jumlah prediksi yang salah dari data yang tidak relevan.

c. FN (False Negative) = Jumlah prediksi yang salah dari data yang tidak relevan.

d. TN (True Negative) $=$ Jumlah prediksi yang benar dari data yang relevan.

Dari tabel 4 dan tabel 5 dapat ditarik kesimpulan bahwa:
a. $\quad$ Nilai $\mathrm{TP}=4$
b. Nilai $\mathrm{FP}=1$
c. Nilai $\mathrm{TN}=0$

\section{d. Nilai $F N=0$}

Sehingga nilai akurasinya adalah:

$$
\begin{aligned}
& \text { Akurasi }=\frac{4+0}{4+0+1+0} \times 100 \% \\
& \text { Akurasi }=\frac{4}{5} \times 100 \% \\
& \text { Akurasi }=80,00 \%
\end{aligned}
$$

Dari uji akurasi dapat disimpulkan bahwa keakuratan dari metode ELECTRE dalam menentukan klasifikasi hotel sebesar $80 \%$.

\section{KESIMPULAN}

Dengan membuat sistem pendukung keputusan yang mengimplementasikan metode ELECTRE dapat memudahkan proses audit yang dilakukan oleh LSUP yang selama ini dilakukan secara manual, serta memudahkan Dinas Pariwisata kota Makassar melaksanakan tugasnya sebagai lembaga yang berkewajiban melakukan pengawasan terhadapa industry pariwisata khususnya Hotel. Pada sistem ini telah dilakukan uji akurasi terhadap hasil yang diberikan, nilai akurasi sebesar $80 \%$.

\section{UCAPAN TERIMA KASIH}

Peneliti mengucapkan terima kasih kepada pihak LSUP dan Dinas Pariwisata kota Makassar, atas waktu dan kesediaannya memberikan data dan wawancara selama penelitian berlangsung. Terima kasih peneliti ucapkan kepada pihak DPRM yang telah memberikan dana hibah sehingga proses penelitian berjalan lancer. Dan terima kasih kepada semua pihak yang telah membantu terlaksananta penelitian ini.

\section{DAFTAR ACUAN}

[1] Undang-undang, "Penjelasan Undang-undang No. 10 2009," 2009.

[2] Permen, "Lampiran PERMEN No. 53 Tahun 2013," pp. 1-60, 2013.

[3] Permen, "Lampiran PERMEN No. 7 Tahun 2014," vol. 3 , 2014.

[4] M. Sianturi, R. Rusiana, M. Sianturi, K. Karyawan, M. Metode, and C. T. Reality, "Sistem Pendukung Keputusan untuk Pemutusan Hubungan Kerja Karyawan Menggunakan Metode Elimination and Choice Translation Reality," vol. 6, no. July, pp. 135-138, 2018.

[5] E. Kurnia and M. F. Ogianta, "Aplikasi Strategi Pemilihan Pemain Futsal Menggunakan Metode Electre," Komputasi J. Ilm. Ilmu Komput. dan Mat., vol. 15, no. 2, pp. 172-181, 
2019.

[6] S. M. Dewi and A. P. Windarto, "Analisis Metode Electre Pada Pemilihan Usaha Kecil Home Industry Yang Tepat Bagi Mahasiswa," Sistemasi, vol. 8, no. 3, p. 377, 2019.

[7] R. Vincentius and A. Hermawan, "Perancangan Aplikasi Social Network Travellers menggunakan Metode Electre," J. Inform. dan Rekayasa Perangkat Lunak, vol. 2, no. 1, p. 7, 2020.

[8] I. Aqli, D. E. Ratnawati, and M. Data, "Sistem Rekomendasi Pemilihan Sekolah Menengah Atas (SMA) Sederajat Kota Malang Menggunakan Metode AHP-ELECTRE Dan SAW," J. Teknol. Inf. dan Ilmu Komput., vol. 4, no. 1, p. 25, 2016.

[9] M. Fahmi Setiawan, Fatma Indriani, "Implementasi Metode
Electre Pada Sistem Pendukung Keputusan SNMPTN Jalur Undangan," Kumpul. J. Ilmu Komput., vol. 02, no. 02, pp. 88101, 2015.

[10] A. P. Windarto and W. P. Mustika, "Penerapan Algoritma ELECTRE pada Pemilihan Cream Pelembab Berdasarkan Konsumen," J. Media Inform. Budidarma, vol. 4, no. 1, p. 229, 2020.

[11] D. N. Triwibowo, A. Kurniadi, and S. Hartinah, "Sistem Pendukung Keputusan Pemilihan Mahasiswa Penerima Beasiswa dengan K-NN dan ELECTRE," Inspir. J. Teknol. Inf. dan Komun., vol. 9, no. 2, p. 89, 2019. 